\title{
Consumer Behavior towards Continued Use of Online Shopping: An Extend Expectation Disconfirmation Model
}

\author{
Min Qin \\ School of Communication, Jiangxi Normal University, P.R. China, 330022 \\ helenqin126@163.com
}

\begin{abstract}
The business-to-consumer is the most visible business type of electronic commerce. Online shopping allows companies to provide product information and direct sales to their consumers. In order to effectively drive consumers to accept electronic commerce and online transactions, there is an urgent need to understand the factors that influence consumer behavior towards continued use of online transactions. The expectation disconfirmation model (EDM) from the consumer behavior literature has been used to explain continued information systems (IS) usage behavior. This paper takes an extend EDM perspective to predict and explain consumer behavior in the online shopping context. This proposed extend EDM, incorporating the perceived risk, trust and shopping enjoyment, was empirically tested with data collected from a survey of online shopping consumers in three websites. The objective of this research is to increase the understanding of consumer online behavior for future research in e-commerce.
\end{abstract}

\section{Introduction}

The advantages of online shopping transactions are well known. The most common incentives for consumers to shop online are convenience, broader selections [1], competitive pricing, and greater access to information [2]. However, online sales volume still remains relatively low compared to alternative retailing forms. Lots of previous research has shown [3, 4] that obvious reasons include security and privacy concerns, lack of familiarity with the medium, and the suitability of products to be sold. Actually in the businessto-consumer electronic commerce, a consumer has the double role of the product consumer and information technology (the website system) user [5]. To the consumer in e-commerce, the website system is a full representation of the shopping. For example, some famous online shopping websites (www. amazon.com, www.buy.com, and so on) heavily depend on information system (IS) in their business strategies. A previous research [6] has shown that system use is a good indicator of the success of commercial websites. In this way,

Please use the following format when citing this chapter:

Qin, M.. 2007, in IFIP International Federation for Information Processing, Volume 25I, Integration and Innovation Orient to L-Society Volumel, Wang, W. (lds), (Boston: Springer), pp. 400-407. 
researchers need to combine the research streams of information systems, consumer psychology, and marketing to study and understand online consumer behavior.

The expectation disconfirmation model (EDM or expectation confirmation model) from consumer behavior literature $[7,8]$ posits that a consumer's repurchase intention is preceded by consumer satisfaction; whereas consumer satisfaction is directly affected by disconfirmation resulted between a consumer's pre-purchase expectations and post-purchase expectations. Bhattacherjee [9] applied this theory to the continued use of the information system, and he integrated the concept of the technology acceptance model (TAM) with the EDM to reflect the influence of a consumer's expectation of systemspecific attributes on consumer satisfaction and the intention of continuous usage. From the viewpoint of information system, the EDM can reasonably explain a consumer's repurchase or continued purchase behavior.

Empirical research has indicated that the effects of online commerce on consumer behavior are not same as the traditional marketing [4]. The perceived risks, trust and shopping enjoyment associated with online shopping can influence attitudes toward online purchase, as does the perceived ease of using the website [10]. Therefore, our study will further extend the EDM to online commerce through adding some constructs. The rest of this paper proceeds as follows. The next section presents the theoretical framework, including reviewing the essence of expectation disconfirmation model, examining the constructs of perceived risk, trust and shopping enjoyment in e-commerce. An extended research model and research hypotheses are then developed in section 3 , and in this section we describe research methodology. Section 4 gives data analysis and empirical results. Research findings and limitations are presented in section 5. Conclusions are given in the final section.

\section{Theoretical Framework}

Online shopping has been viewed as the new business model. As both the presence and operation of online shopping depend heavily on IT, they are often regarded as a type of IS [11]. To companies, online shopping commerce is their strategic information systems (IS), while to consumers, online shopping commerce is end-user of IS. This view is justified by previous literature [12, 13]. Hence, when consumers accept and use online shopping, they are accepting and using IS. In order to keep old consumers using online shopping, it is need to understand their post-adoption behavior of IS. Based on these perspectives, our study employs the theoretical constructs of EDM and perceived risks, trust, perceived enjoyment to predict and explain consumer behavior towards continued use of online shopping.

\subsection{Expectation Disconfirmation Model}

Since a large portion of consumer purchases are second or $n$-time purchases rather than initial acceptances, the study of consumer repurchase behavior continues to catch the attention from researchers [7]. The EDM explains the consumer consumption decision in the post-purchase process and constantly dominates academic research and managerial practice [8]. According to the 
EDM, the consumers' post-purchase intention is chiefly determined by their satisfaction with actual use of that purchase or service. Satisfied users repurchase that product or continue accepting the service, while dissatisfied consumers stop using it subsequently. Satisfaction is viewed as the key to building and retaining a loyal base of long-term consumers. Investing in customer satisfaction is like taking out an insurance policy, and if some temporary hardship befalls the firm, customers will be more likely to remain loyal [15].

\subsection{Electronic Commerce Acceptance and Continued Usage}

A website is, in essence, an information system. Some prior research has reasonably validated online purchase intentions in part with the technology acceptance model proposed by Davis $[16,17]$, which is preeminent theory of technology acceptance in IS research. As such, online continuous purchase behavior also should be explained in part by the EDM, which is widely supported in IS post-adoption research.

\subsection{Trust, Perceived Risk, and Shopping Enjoyment in E-Commerce}

There are various conceptions of trust in the literature. Nevertheless trust can be described as the belief that the other party will behave in a socially responsible manner, and by so doing, will fulfill the trusting party's expectations without taking advantage of its vulnerabilities [18]. The common Trust has always been an important element in influencing consumer behavior and has been shown to be of high significance in uncertain environments, such as the Internet-based ecommerce context $[19,20]$. Some previous research has proposed trust as an important element of business-to-consumer e-commerce. For example, Palmer, Bailey, and Faraj argue that building consumer trust in web retailers is essential for the growth of $\mathrm{B} 2 \mathrm{C}$ e-commerce [21].

When engaging in an online transaction process, consumers are rightly alarmed about the different types of risks that confront them. But since risk is difficult to capture as an objective reality, the literature predominantly has addressed the notion of perceived risk, which will be defined as the consumer's subjective belief of suffering a loss in pursuit of a desired outcome [22].

Shopping can be intrinsically enjoyment, and enjoyment of the shopping experience is an important determinant of consumer behavior [18]. On the website, shopping enjoyment is positively and significantly related both to attitude toward shopping on the web and intentions toward shopping on the web [23].

\section{Research methodology}

\subsection{An Extended Model and Research Hypotheses}

A consumer's behavioral intention towards continued online shopping in ecommerce should incorporate consumer satisfaction and trust, perceived risk, shopping enjoyment. Based on the theoretical statement from EDM and attituderelated theoretical constructs influencing the online consumer behavior in ecommerce, we develop an extended research model in Fig 1. 


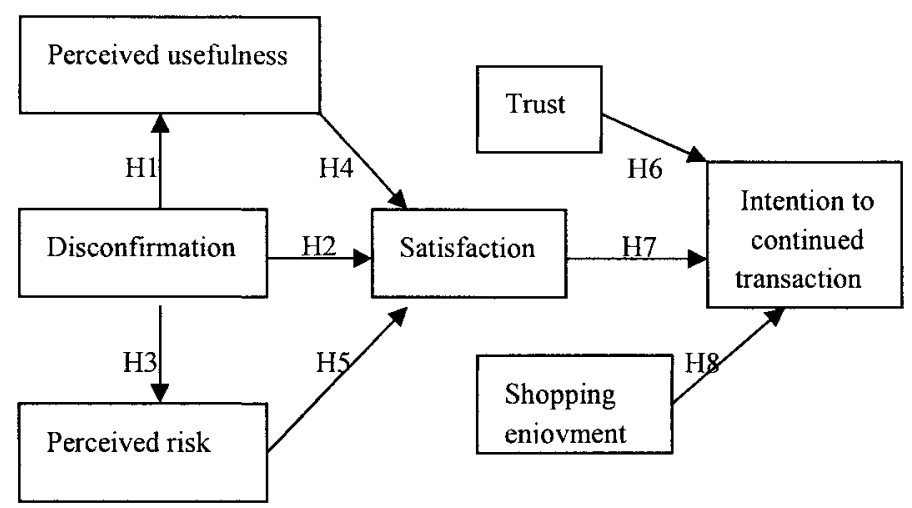

Fig. 6. An Extended Expectation Disconfirmation Model for Online Consumer Behavior

The conceptual model adopts attempts to synthesize the essence of the EDM and three important constructs in e-commerce to predict and explain a consumer's behavioral intention toward online shopping continuance. Hence, we derived the following hypotheses:

Hypothesis 1: consumers' disconfirmation will positively affect their perceived usefulness of online shopping

Hypothesis 2: consumers' disconfirmation will positively influence their satisfaction.

Hypothesis 3: consumers' disconfirmation will negatively affect their perceived risk of online shopping

Hypothesis 4: consumers' perceived usefulness of online shopping will positively influence their satisfaction

Hypothesis 5: consumers' perceived risk of online shopping will negatively influence their satisfaction

Hypothesis 6: consumers' trust will positively affect their intention to continued transaction

Hypothesis 7: consumers' satisfaction will positively influence their intention to continued transaction

Hypothesis 8: consumers' shopping enjoyment will positively affect their intention to continued transaction

\subsection{Measure Development}

The measure of EDM was developed on the constructs of perceived usefulness, disconfirmation, satisfaction, and intention toward continued transaction. Perceived usefulness was measured using a 4-item scale adapted from Davis et al. [24]. Disconfirmation, satisfaction and intention to continued transaction were adapted from Bhattacherjee [9], and they were measured using a 3-item scale, 4-item scale, and 3-item scale respectively. Measures for trust and perceived risk were adapted from Jarvenpaa et al. [19], both of which include three items. Shopping enjoyment was measured using a 3 -item scale consistent from the previous research $[25,26]$. All of the above 23 items were measured on 
a 5-point Likert scale ranging from one (strongly disagree) to five (strongly agree).

\subsection{Sample and Data Collection}

In this study, we adopted the methodology of survey research. The sampling units are registered users of three online shopping websites (www.ncgift.com, www.jxxhsd.com and www.qingyuanbook.com) in the district of Jiangxi, which sell the products of the gifts and various books. The questionnaire of 23 items was developed to measure the seven latent constructs. An electronic mail message, which explained the objectives of the research, was attached our questionnaire. Both of them were distributed to the 863 registered users of three websites through e-mail.

Each respondent was asked to provide the name of online shopping websites that he had used and had purchased the products at least one time during the last 12 months. If respondent had the online purchase experience, then they were instructed to answer all the questions from the questionnaire. Finally, 179 registered users were found to have the online shopping experience, and 156 questionnaires are complete and usable.

\section{Data Analysis and Results}

Table 7. Confirmatory factor analysis for convergent validity

\begin{tabular}{|c|c|c|c|c|c|c|c|c|c|}
\hline \multirow{2}{*}{$\begin{array}{l}\text { Constr } \\
\text { uct }\end{array}$} & \multirow{2}{*}{$\begin{array}{l}\text { Item } \\
\text { loading }\end{array}$} & \multirow{2}{*}{$\begin{array}{l}\text { Composite } \\
\text { reliability }\end{array}$} & \multirow[t]{2}{*}{ AVE } & \multicolumn{6}{|c|}{ Factor correlations } \\
\hline & & & & PU & DCO & PR & SE & SAT TR & nT \\
\hline $\mathrm{PU}$ & $0.83-0.90$ & 0.86 & 0.76 & 0.76 & & & & & \\
\hline $\mathrm{DCO}$ & $0.75-0.87$ & 0.82 & 0.68 & 0.51 & 0.68 & & & & \\
\hline $\mathrm{PR}$ & $0.82-0.88$ & 0.85 & 0.73 & -0.52 & -0.43 & 0.73 & & & \\
\hline$S E$ & $0.74-0.85$ & 0.81 & 0.64 & 0.45 & 0.36 & -0.30 & 0.64 & & \\
\hline SAT & $0.82-0.90$ & 0.86 & 0.77 & 0.55 & 0.38 & -0.44 & 0.40 & 0.77 & \\
\hline TR & $0.72-0.86$ & 0.83 & 0.70 & 0.48 & 0.42 & -0.39 & 0.33 & $\begin{array}{lll}0.41 & 0.70\end{array}$ & \\
\hline INT & $0.82-0.91$ & 0.87 & 0.80 & 0.58 & 0.37 & -0.43 & 0.42 & 0.510 .48 & 0.80 \\
\hline
\end{tabular}

The seven hypotheses were tested collectively using the structural equation modeling (SEM).The data obtained were tested for reliability and validity using confirmatory factor analysis (CFA). The measurement model includes 23 items describing seven latent constructs: Perceived usefulness (PU), Disconfirmation (DCO), Perceived risk (PR), Shopping enjoyment (SE), Satisfaction (SAT), Trust (TR), Intention to continued transaction (INT).

Convergent validity is assessed using three criteria, including all factor loadings should be exceed 0.7 ; construct reliabilities should be exceed 0.8 ; and average variance extracted (AVE) exceed 0.5 . As we can see from Table.1, composite reliabilities of all constructs exceeded 0.80 . The CFA results indicate that all 23 items corresponding to the seven constructs had loadings value ranged between 0.72 and 0.91 . The square root of AVE ranged from 0.81 to 0.87 . Hence, all three conditions for convergent validity were met. 
Discriminant validity assesses whether individual indicators can adequately distinguish between different constructs. The correlation matrix in Table. 1 indicates that the square root of AVE of each construct (diagonal elements) was higher than corresponding correlation values for that variable in most cases, so this can assure discriminant validity.

The next step in the data analysis was to examine the significance and strength of each hypothesized effect. Examining individual paths, we can see that all paths were significant. Intention towards online continued transaction was predicted by satisfaction $(0.32 ; p<0.001)$, trust $(0.23 ; p<0.001)$ and shopping enjoyment $(0.14 ; p<0.001)$, which jointly explained $68 \%$ of the variance in intention. Consumer satisfaction is predicted by disconfirmation $((0.48$; $p<0.001)$, perceived usefulness $(0.12 ; p<0.001)$, and perceived risk $(-0.21$; $p<0.001$ ). It supports $\mathrm{H} 2, \mathrm{H} 4$ and $\mathrm{H} 5$ respectively. Supporting H1and H3, disconfirmation had positive effect on perceived usefulness and negatively effect on perceived risk. In summary, all hypotheses were supported.

\section{Research findings and limitations}

This study attempts to harmonize the essence of EDM and other consumerrelated factors in online shopping to develop an extended EDM for explaining consumer's continued behavior of online shopping. From the current research model, some interesting findings can be discussed. First, trust and shopping enjoyment also are identified as two motivators of behavioral intention towards continuous use of online shopping. The effect of shopping enjoyment is much lower than both trust and satisfaction. To some extent, when consumers accept the online shopping, they pay more attention to the products themselves. Secondly, perceived risk is identified to have a direct effect on the consumer's satisfaction in this study, and its effect on satisfaction is greater than perceived usefulness. Thirdly, different from the EDM, continued use of online shopping in e-commerce may not have one motivator of satisfaction to measure.

Like most empirical research, this study is not without limitations. On the one hand, we employed consumers of three online shopping websites as the sample, and the categories of provided products are limited. The empirical results in this study may have limited to the general products. On the other hand, we do not strictly distinguish the consumers of continued using online shopping system from continued purchase the products with online shopping. The future research will make much effort on these aspects.

\section{Conclusions}

This paper has devoted much effort on developing an extended expectation disconfirmation model to predict and explain the consumer's continued use of online shopping. Empirical data was collected from three online shopping websites users to verify the fitness of the hypothetical model. This research findings show that a consumer's behavioral intention towards online shopping continuance is influenced by satisfaction, trust and shopping enjoyment. Perceived risk has positively effect on the consumer satisfaction. The main 
purpose of study is to provide the deeper understandings of consumer behavior towards continued use of online shopping.

\section{References}

1. S.L. Jarvenpaa and P.A. Todd, Consumer Reactions to Electronic Shopping on the World Wide Web, International Journal of Electronic Commerce,1(2), 58-88 (1997).

2. R.A. Peterson, S. Balasubramanian and B.J. Bronnenberg, Exploring the Implications of the Internet for Consumer Marketing, Journal of the Academy of Marketing Science, 25(4), 329-346 (1997).

3. S. Bellman, G.L. Lohse and E.J. Johnson, Predictors of Online Buying Behavior, Communications of the ACM 42(12), 32-38 (1999).

4. I. Maignan and B.A. Lukas, The Nature and Social Uses of the Internet: A Qualitative Investigation, Journal of Consumer Affairs 31(2), 346-371 (1997).

5. M. Koufaris, A. Kambil and P.A. LaBarbera, Consumer Behavior in Web-Based Commerce: An Empirical Study, International Journal of Electronic Commerce, 6(2), 115-138 (2001).

6. C. Liu and K.P. Arnett, Exploring the Factors Associated with Web Site Success in the Context of Electronic Commerce, Information \& Management, 38(1), 23-33 (2000).

7. R.L. Oliver, Cognitive, Affective, and Attribute Bases of the Satisfaction Response, Journal of Consumer Research ,20, 418-430 (1993).

8. R.A. Spreng, S.B. MacKenzie and R.W. Olshavsky, A Reexamination of the Determinants of Consumer Satisfaction, Journal of Marketing ,60(July), 1532 (1996).

9. A. Bhattacherjee, Understanding Information System Continuance: An Expectation-Confirmation Model, MIS Quarterly, 25(3), 351-370 (2001).

10. H.v.D. Heijden, T. Verhagen and M. Creemers, Predicting Online Purchase Behavior: Replications and Test of Competing Models, In proceedings of the $34^{\text {th }}$ Hawaii International Conference on System Sciences, IEEE Computer Society Press, (2001).

11. L.-d. Chen, M.L. Gillenson and D.L. Sherrell, Enticing Online Consumers: An Extended Technology Acceptance Perspective, Information \& Management, 39, 705-719 (2002).

12. S. Pant and C. Hsu, Business on the Web: Strategies and Economics, Computer Networks and ISDN Systems ,28(7-11), 1481-1492 (1996).

13. P. Spiller and G.L. Lohse, A Classification of Internet Retail Store, International Journal of Electronic Commerce ,2(2), 29-56 (1997).

14. C. Liao, J.L. Chen and D.C. Yen, Theory of Planning Behavior (TPB) and Customer Satisfaction in the Continued Use of E-Service: An Integrated Model, Computers in Human Behavior (2006).

15 E. W. Anderson and M. W. Sullivan, The Antecedents and Consequences of Customer Satisfaction for Firms, Marketing Scienc,e 12(2), 125-143 (1993).

16. D. Gefen, E. Karahanna and D.W. Straub, Trust and TAM in Online Shopping: An Integrated Model, MIS Quarterly ,27(1), 51-90 (2003).

17. F. D. Davis, Perceived usefulness, Perceived ease of use, and user Acceptance of information technology, MIS Quarterly, 13(3), 319-340 (1989). 
18. P.A. Pavlou, Consumer Acceptance of Electronic Commerce: Integrating Trust and Risk with the Technology Acceptance Model, International Journal of Electronic Commerce, 7(3), 101-134 (2003).

19. S.L. Jarvenpaa, N. Tractinsky and M. Vitale, Consumer Trust in an Internet Store, Information Technology and Management, 1(12), 45-71 (1999).

20. J-M. Moon and Y-G. Kim, Extending the TAM for a World-Wide-Web Context, Information and Management , 28, 217-230 (2001).

21. J.W. Palmer, J.P. Bailey and S. Faraj, The Role of Intermediaries in the Development of Trust on the WWW: The Use and Prominence of Trusted Third Parties and Privacy Statements, Journal of Computer Mediated Communication, $5(3), 2000$.

22.R.A. Bauer, Consumer Behavior As Risk Taking .In D.F.Cox (ed.), Risk Taking and Information Handling in Consumer Behavior, Cambridge: Harvard University Press,389-398(1960).

23. S.L. Jarvenpaa and P.A. Todd, Consumer Reactions to Electronic Shopping on the World Wide Web, International Journal of Electronic Commerce, 1(2), 59-88 (1997).

24. F.D. Davis, R.P Bagozzi and P.R Warshaw, User Acceptance of Computer Technology: A Comparison of Two Theoretical Models, Management Science, 35(8), 983-1003 (1989).

25. D. Compeau, C.A. Higgins and S. Huff, Social Cognitive Theory and Individual Reactions to Computer Technology: A Longitudinal Study, MIS Quarterly ,23(2), 145-158 (1999).

26. M.B. Holbrook, R.W. Chestnut, T.A. Oliva and E.A. Greenleaf, Play As a Consumption Experience: The Roles of Emotions, Performance, and Personality in the Enjoyment of Games, Journal of Consumer Research ,11, 728-739 (1984). 